\title{
Pigeon Pea [Cajanus cajan (L.)]: New Promising Host of Lac [Kerria lacca (Kerr)] in Southern Rajasthan
}

\author{
H. Swami, Lekha, Gaurang Chhangani, N.L. Regar
}

10.18805/IJARe.A-5797

\begin{abstract}
Background: Lac is a resin secretion of insects [Kerria lacca (Kerr)], which are commercially cultivated through ages. Lac cultivation has its roots in India and a major source of economy to the local populace. Though different lac hosts have been recorded in Rajasthan, but it is not cultivated commercially. Pigeonpea crop could be utilized for encouraging lac cultivation in the region and yield losses can be compensated by additional income received from lac resin.

Methods: The experiment on "Studies on Economics and Yield Attributing Parameters of Lac Cultivation on Yield of Pigeonpea, Cajanus cajan (L.) in Southern Rajasthan" was conducted on Rangeeni strain of lac insect in Baisakhi season at lac insect gene bank cum garden situated at Department of Entomology, Rajasthan College of Agriculture, MPUAT, Udaipur during 2019-20 and 2020-21 respectively. The life cycle of Rangeeni strain of lac insect were studied on pigeonpea sown in last week of August in plot size measuring $2 \times 10 \mathrm{sq} \mathrm{m}$ during Baisakhi season of both year.

Result: The study revealed that the mean initial settlement density of lac insect on pigeonpea ranged from 67.53 to 84.20 with 4.27 to 5.27 (per sq. $\mathrm{cm}$ ) mature female cell density during successive years. The mean per cent settlement was found to be the maximum $(91.78$ and $91.15 \%)$ at lower portion of the pigeonpea plant during respective years. The duration of sex differentiation ranged from 48.23 to 49.10 days for both successive years. The benefit cost ratio was also higher (1.95 and 2.09) in lac inoculated experiment then the sole seed crop (control) of pigeon pea (1.84 and 1.35) in season 2019-20 and 2020-21, respectively. All the parameter revealed that pigeon pea is economically efficient host for the Rangeeni strain of lac in agro-climatic region of southern Rajasthan.
\end{abstract}

Key words: Benefit cost ratio, Lac, Life cycle, Pigeon pea, Rangeeni, Yield.

\section{INTRODUCTION}

Lac insect, Kerria lacca (Kerr) belongs to the family Tachardiidae (Kerriidae), super family Coccoidea of the order Hemiptera. Lac is a soft bodied insect which secrets resin through minute openings in the form of lac to protect its body. The life cycle of lac insect starts with the crawlers, after settlement the nymphs undergo three successive moults to become an adult. The first instar is mobile and crawls over the tender shoot of host trees and settles to feed on phloem sap by piercing its proboscis into phloem region of shoot. To avoid covering of these holes by resin, the lac insect secretes wax, which is white thread-like structure. The duration of each stage depends on the host plant species on which it feeds, lac crop and prevailing environmental conditions (Mohanta et al., 2014). The lac insect basically yields three useful materials viz., resin, dye and wax. The major constituent of lac is the resin (68\%), which is a polyester complex of straight chain of hydroxy fatty acids ( C14-C18 carbon chain, such as aleuritic acid and butolic acids), mono and di-hydroxy acids along with hydroxy terpenic acids. Resin is commonly known as "lac" and is sold in the market as shellac or seedlac or button lac. Other constituents present are dye (1.2\%), wax (6\%), others $(25 \%)$ like sugar, proteins, soluble salts, sand, woody matter and insect body debris (Singh, 2006). The lac ecosystem fauna includes 87 species of lac insect belonging to nine genera recorded from all over the world. Though different lac hosts have been recorded in Rajasthan, but it
Department of Entomology, Rajasthan College of Agriculture, Maharana Pratap University of Agriculture and Technology, Udaipur313 001, Rajasthan, India.

Corresponding Author: Gaurang Chhangani, Department of Entomology, Rajasthan College of Agriculture, Maharana Pratap University of Agriculture and Technology, Udaipur-313 001, Rajasthan, India. Email: gaurangchhangani@gmail.com

How to cite this article: Swami, H., Lekha, Chhangani, G. and Regar, N.L. (2021). Pigeon Pea [Cajanus cajan (L.)]: New Promising Host of Lac [Kerria lacca (Kerr)] in Southern Rajasthan. Indian Journal of Agricultural Research. DOI: 10.18805/IJARe.A-5797.

Submitted: 19-04-2021 Accepted: 17-07-2021 Online: 06-09-2021

is not cultivated commercially. In Rajasthan lac insect naturally found in abundance on various hosts (Swami et al. 2017).

Pigeon pea, (Cajanus cajan L.) is a newhost of lac and different strains of lac insects are being investigated to enhance its production. On-farm production of lac on Pigeon pea resulted in increased demand of lac in China and spread the lac cultivation in the Northern part of The Lao Peoples Democratic Republic (Lao PDR). Ghosh et al. (2014) also reported pigeonpeaas a promising host in North-East India. It is also recorded as suitable host for lac insect, $K$. lacca in Southern Rajasthan (Kalahal, 2017). Pigeonpea is widely cultivated as pulse crop in different parts of the state which 
Pigeon Pea [Cajanus cajan(L.)]: New Promising Host of Lac [Kerria lacca (Kerr)] in Southern Rajasthan

could be utilized for encouraging lac cultivation in the region. Though lac cultivation has been reported to influence the seed yielding capability of host plant, but the seed yield loss can be compensated by additional income received from selling the lac resin. Therefore, in addition to the advantage of cultivation of lac insect on Pigeon pea, it is essential to study the effect of lac cultivation on yield of Pigeon pea, which will bring an impetus to lac cultivation in the area. Hence, the present research work on Economics and Yield Attributing Parameters of Lac Cultivation on yield of Pigeon pea, Cajanus cajan (L.) in Southern Rajasthan was carried out during two successive year 2019-20 and 2020-21.

\section{MATERIALS AND METHODS}

The experiment was conducted on Rangeeni strain of lac insect in Baisakhi season at lac insect gene bank cum garden situated at Department of Entomology, Rajasthan College of Agriculture, MPUAT, Udaipur during 2019-20 and 2020-21. The healthy host plants of arhar were raised by following all the agronomic practices. The local perennial variety of Pigeon pea was sown to get healthy plants of proper age for lac inoculation with brood lac sticks. The crop was sown in the last week of August in both year with row to row spacing of $100 \mathrm{~cm}$ and plant to plant spacing of $40 \mathrm{~cm}$ in plot size measuring $2 \times 10 \mathrm{sq} \mathrm{m}$. There were 50 plants in each set of experiment which replicated thrice. The brood lac of Rangeeni strain needed for the experimentwere collected from the mature Katki crop of Rangeeni strain prevailing in the region on its natural hosts bearing fully matured females. The brood lac were bundled and tied in the month of October-November on host plants at 1-1.5 ft above the ground level to provide succulent stem for crawlers to settle down. The brood lac bundles were tied in 60 micron nylon mesh which allows only crawlers to move out retaining the parasitoids inside if any emerges simultaneously with the lac insect crawlers. The nymphs were allowed to emerge from mature females for about two weeks. After the emergence of newly hatched nymphs the phunki lac stick bundles were removed from host plants. Nymph/crawlers of the lac insect were allowed to settle on the one meter length of the succulent stem of pigeonpea. The nymph population settled on the stems of plant more than one meter length were scrapped off with the help of knife and the observations on the different parameters of life cycle of the Rangeeni strain of lac insect population prevailing on this part of the stems of 10 tagged plants each was recorded separately.The ten tagged and labeled plants of the three replications of lac inoculated and control plot were utilized to record the different yield attributing traits of plants in 201920 and 2020-21 respectively.

\section{Observations}

To study the life cycle of Rangeeni strain lac insect on pigeonpea, regular observations were recorded on different parameters like initial density of settlement, mortality, final density of settlement, percent settlement, duration in days for sex differentiation, density at crop maturity, recorded on the tagged ten plants in three sets of experiment which started from two weeks after the inoculation of brood lac as per the standard procedure prescribed by Mohanasundaram, et al. (2016).

The different yield attributing traits of pigeonpea viz., plant height $(\mathrm{cm})$, number of branches per plant, number of pods per branch, number of seeds per pod, seed yield per plant $(\mathrm{gm})$ and weight of 100 seeds were recorded from three set of lac inoculated experiment and control from ten randomly selected and tagged plants. The mature pods were harvested in the months of March-April through hand picking from the lac inoculated plants and without lac inoculated plants separately and dried to record observations.

The seed yield of pigeonpea from lac inoculated experiment and sole experiment (control) were recorded separately and computed as seed yield per ha. The scrapped lac yield in lac inoculated experiment was recorded and computed as yield per ha. The economics of lac cultivation and sole seed crop of pigeonpea was analyzed by Benefit cost ratio $(\mathrm{BCR})$ :

$$
\text { Benefit cost ratio }(B C R)=\frac{\text { Profit }}{\text { Total cost of cultivation }}
$$

\section{RESULTS AND DISCUSSION}

The gravid female lays eggs inside encrustation and first instars larvae hatch out which crawls and settle at suitable sites on succulent stem of host plant. The settlement of the first instar crawlers takes place within a period of a week or two of the hatching. The observations of mean initial density of settlement of crawlers recorded 7 days after the inoculation of broodlac and there were a difference in a mean initial density of settlement of first instar crawlers on lower, middle and upper portion of plant. The observed mean initial settlement of first instar crawlers of Rangeeni strain of lac insect on Pigeon pea in Baisakhi season during 2019-20 and 2020-21 were 79.37, 77.10, 66.37 and 84.20,81.30,67.53 crawlers per sq.cm respectively on lower, middle and upper portion of host plant in three set of experiment. The mean final density of settlement of first instar crawlers were recorded $72.97,70.13,59.53$ and 76.90,73.13,60.00 crawlers per sq.cm in both year, respectively on lower, middle and upper portion of host plant in three set of experiment. The data reveal that maximum mean final density of settlement of crawlers observed were 76.90 crawlers per sq.cm; while, minimum mean final density of settlement of crawlers of Rangeeni strain of lac insect were 59.53 crawlers per sq.cm on lower portion of Pigeon pea in during Baisakhi season of 201920 . The mean per cent settlement of crawlers in three set of experiments were observed $91.78,90.73,89.16$ and 91.15 , $89.89,88.83$ on lower, middle and upper portion of plant in 2019-20 and 2020-21, respectively (Table 2).

The results of present investigations are in alignment with the findings of Divakara (2013), who recorded maximum density $\left(77.8\right.$ crawlers $\left./ \mathrm{cm}^{2}\right)$ of insect settlement in $F$. macrophylla as intercrop in understorey of Dalbergia sissoo 
after 21 days of brood lac inoculation. Similarly, Mohanta et al (2014) who reported that initial density of settlement of larvae ranged between 92.58-126.74 crawlers per sq.cm and 93.12-109.62 crawlers per sq.cm of lac strain on Kusum and Ber trees, respectively.

The first instar crawlers which could not find suitable sites for settlement on host plant could not survive and dies due to starvation within a week or two of its emergence. The observations on per cent initial mortality of first instar crawlers recorded at 21 days after inoculation of brood lac of Rangeeni strain of lac insect in Baisakhi season on Pigeon pea during 2019-20 and 2020-21. The per cent mean mortality was observed to be 8.06, 9.04, 10.30 and 8.67, 10.05, 11.15 from lower, middle and upper portion of the plants in three set of experiment in both year, respectively (Table 2). The results of the present investigation confer the findings of Divakara (2013) who recorded minimum per cent mortality of Rangeeni strain of lac insect in C. calothyrsus (12.48\%) and $D$. assamica (22.36\%) and maximum per cent mortality of Kusmi strain in Jethwi season in F. semialata (27.88\%) followed by ber (24.91\%) and kusum (18.75\%). Kalahal et al. (2017) reported that mean mortality of Rangeeni strain of lac insect in Pigeon pea were $7.55 \%, 8.12 \%, 10.39 \%$; $7.70 \%, 6.46 \%, 7.49 \%$ and $9.09 \%, 12.27 \%, 12.58 \%$ at lower, middle and upper portion of plant in three plots respectively; confirming the present findings.

Table 1: Mean initial, final and mature female cells density of lac insect on Pigeon pea during Baisakhi season, 2019-20 and 2020-21.

\begin{tabular}{|c|c|c|c|c|c|c|c|c|c|}
\hline \multirow[t]{2}{*}{ Parameters } & \multicolumn{3}{|c|}{$\begin{array}{l}\text { Mean initial density of settlement } \\
\text { (per sq.cm) }\end{array}$} & \multicolumn{3}{|c|}{$\begin{array}{l}\text { Mean final density of settlement } \\
\text { (per sq.cm) }\end{array}$} & \multicolumn{3}{|c|}{$\begin{array}{l}\text { Mature female cells density } \\
\text { (per sq.cm) }\end{array}$} \\
\hline & Lower & Middle & Upper & Lower & Middle & Upper & Lower & Middle & Upper \\
\hline & \multicolumn{9}{|c|}{ 2019-20 } \\
\hline Mean density $(\chi)$ & 79.37 & 77.10 & 66.37 & 72.97 & 70.13 & 59.53 & 4.27 & 4.97 & 4.57 \\
\hline $\mathrm{SD}(\sigma)$ & 6.82 & 4.36 & 3.35 & 5.91 & 3.98 & 2.61 & 0.15 & 0.85 & 0.67 \\
\hline \multirow[t]{2}{*}{ SE } & 3.35 & 2.52 & 1.93 & 3.41 & 2.30 & 1.51 & 0.09 & 0.49 & 0.38 \\
\hline & \multicolumn{9}{|c|}{$2020-21$} \\
\hline Mean density $(\chi)$ & 84.20 & 81.30 & 67.53 & 76.90 & 73.13 & 60.00 & 5.27 & 4.93 & 5.20 \\
\hline \multicolumn{10}{|l|}{$\mathrm{SD}(\sigma)$} \\
\hline & 5.71 & 5.41 & 1.53 & 5.98 & 5.43 & 1.61 & 0.40 & 0.25 & 0.17 \\
\hline SE & 3.30 & 3.12 & 0.88 & 3.45 & 3.13 & 0.93 & 0.23 & 0.15 & 0.10 \\
\hline
\end{tabular}

Table 2: Mean per cent settlement,mortality and mean duration (days) of sex differentiationof lac insect on Pigeon pea during Baisakhi season, 2019-20 and 2020-21.

\begin{tabular}{lccr}
\hline Year & & Mean per cent settlement & \\
\cline { 2 - 4 } $2019-20$ & Lower portion & Middle portion & Upper portion \\
$2020-21$ & 91.78 & 90.73 & 89.16 \\
& 91.15 & 89.89 & 88.83 \\
$2019-20$ & & Mean per cent mortality per sq.cm & 10.30 \\
$2020-21$ & 8.06 & 9.04 & 11.15 \\
$2019-20$ & 8.67 & 10.05 & 48.23 \\
$2020-21$ & 49.10 & Mean duration (days) of sex differentiation & 48.70 \\
\hline
\end{tabular}

Table 3: Effect of lac cultivation on yield parameters of Pigeon pea during Baisakhi season, 2019-20 and 2020-21.

\begin{tabular}{|c|c|c|c|c|c|c|c|}
\hline \multirow{2}{*}{ Experiment } & \multicolumn{7}{|c|}{ Mean } \\
\hline & $\begin{array}{l}\text { Plant height } \\
\text { (cm) }\end{array}$ & $\begin{array}{l}\text { Branches/ } \\
\text { plant (no.) }\end{array}$ & $\begin{array}{c}\text { Pods/ } \\
\text { branch (no.) }\end{array}$ & $\begin{array}{l}\text { Seeds/ } \\
\text { pod (no.) }\end{array}$ & $\begin{array}{l}\text { Seed yield } \\
\text { /plant(gm) }\end{array}$ & $\begin{array}{c}\text { Seed yield } \\
\text { (kg/ha) }\end{array}$ & $\begin{array}{c}\text { Weight of } 100 \\
\text { seeds (gm) }\end{array}$ \\
\hline \multicolumn{8}{|c|}{ A. Lac inoculated all three experiment } \\
\hline 2019-20 & 161.30 & 11.53 & 4.40 & 3.57 & 24.13 & 603.33 & 7.63 \\
\hline $2020-21$ & 161.06 & 11.63 & 4.37 & 3.70 & 24.13 & 603.33 & 7.27 \\
\hline \multicolumn{8}{|l|}{ B. Control } \\
\hline 2019-20 & 172.70 & 11.90 & 4.60 & 3.70 & 35.80 & 895.00 & 8.70 \\
\hline $2020-21$ & 170.90 & 12.30 & 4.80 & 4.10 & 30.10 & 752.50 & 8.30 \\
\hline \multicolumn{8}{|c|}{ C. Per cent decrease in lac inoculated experiment } \\
\hline 2019-20 & $6.60 \%$ & $3.08 \%$ & $4.35 \%$ & $3.60 \%$ & $32.59 \%$ & $32.59 \%$ & $12.26 \%$ \\
\hline $2020-21$ & $5.75 \%$ & $5.42 \%$ & $9.03 \%$ & $9.76 \%$ & $19.82 \%$ & $19.82 \%$ & $12.45 \%$ \\
\hline
\end{tabular}


Pigeon Pea [Cajanus cajan(L.)]: New Promising Host of Lac [Kerria lacca (Kerr)] in Southern Rajasthan

The duration of sex differentiation of Rangeeni strain of lac insect on lower, middle and upper portion of plants in three set of experiments were $49.10,48.83,48.23$ and 48.97 , 48.60, 48.70days, 2019-20 and 2020-21, respectively (Table 2). The present investigation close conformity with findings of Swami et al. (2017), who reported that time elapsed between date of inoculation to male and female differentiation of lac insect recorded as duration of pre sexual stages (days) varied from 47 to 51 days on 10 pigeon pea plants in three set of plots.

The mean density of female cell recorded at crop maturity were 4.27, 4.97, 4.57 and 5.27, 4.93, 5.20 female cells per sq.cm in 2019-20 and 2020-21, respectively on lower, middle and upper portion of plant in three set of experiment. The maximum mean density of female cells of Rangeeni strain of lac insect on pigeonpea, ranged from 4.27 to 4.97 per sq.cm and 4.93 to 5.27 per sq.cm during Baisakhi season of both year, respectively (Table 1). The results of present investigation are in full alignment with the findings of Mohanta et al. (2014) who also recorded average density of living female cells at crop maturity were 3.3812.67 cells per sq.cm on palas plant for Rangeeni strain of lac insect. Similarly, Kalahalet al. (2017), who reported that the density of female cells during maturity ranged from 01 11 cells per sq.cm on Pigeon pea for Rangeeni strain of lac insect.

The mean plant height, number of branches per plant, number of pods per branch, number of seeds per pod, seed yield per plant and weight of 100 seeds in lac inoculated were $161.30 \mathrm{~cm}, 11.53,4.40,3.57,24.13 \mathrm{gm}$ and $7.63 \mathrm{gm}$ in first year and $161.06 \mathrm{~cm}, 11.63,4.37,3.70,24.00 \mathrm{gm}$ and $7.27 \mathrm{gm}$, observed in second year, respectively (Table 3 ). The mean seed yield in lac inoculated experiment and control experiment 2019-20 and 2020-21 were 603.33, 603.33 and $895.00,752.50 \mathrm{~kg} / \mathrm{ha}$, respectively. The per cent decrease in both year plant height, number of branches per plant, number of pods per branch, number of seeds per pod, seed yield per plant and weight of 100 seeds in first year lac inoculated pigeonpea were 6.60, 3.08, 4.35, 3.60, 32.59 and $12.26 \%$ respectively and in second year lac inoculated pigeonpea were $5.75,5.42,9.03,9.96,19.82$ and $12.45 \%$ respectively.

The findings of present investigation are almost similar as observed by Ghosh et al. (2014), Lohot et al. (2018) and Ghosh et al. (2018). Gosh et al. (2014), who reported that rearing of lac insect on Pigeon pea reduced weight of 100 seeds $(13.03 \%)$ and grain yield per plant $(12.08 \%)$ significantly. Similarly, Lohat et al. (2018) observed that lac culture decreased 100 seed weight (5.4\%) and seed yield $(10.5 \%)$ of Pigeon pea.

The Benefit cost ratio of lac inoculated experiment was more (1.95 and 2.09) than sole seed crop of Pigeon pea (1.84and 1.35) in both year, respectively i.e. lac inoculation gave maximum profit (Table 4). The result was found similar to the finding of Lohot et al. (2018), who reported that additional income from lac cultivation and income from selling seed as sole crop Assam local-1 (12.8\%), Assam

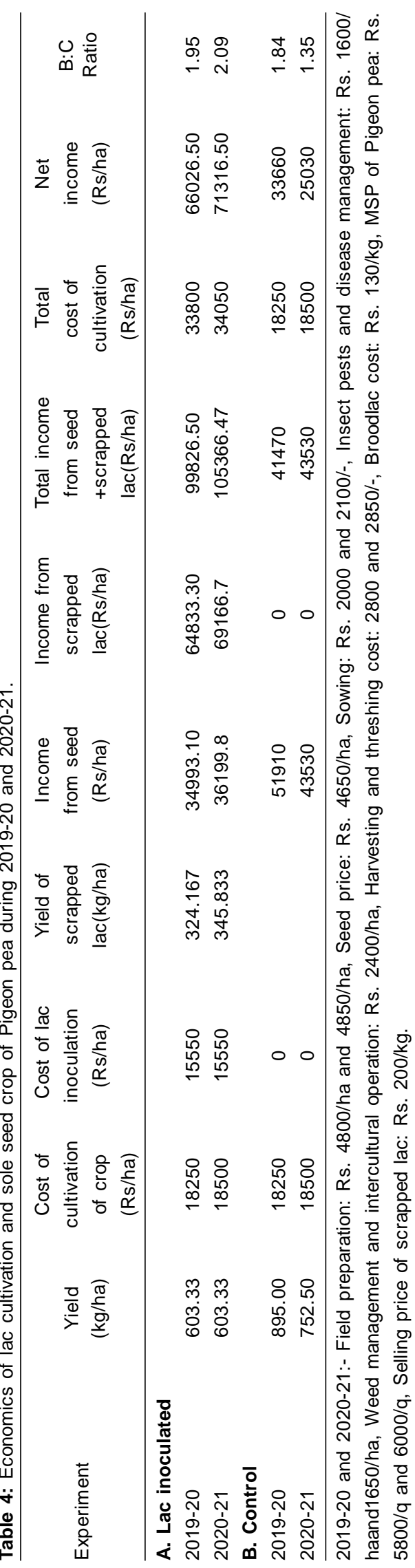

Indian Journal of Agricultural Research 
local-2 (17.1\%) and RCMP-5 (27.2\%) had significantly higher profit per cent as compared to control (sole seed crop). The present findings are in agreement with the findings of Kumari et al. (2019) and Kandasamy et al. (2020) who reported Pigeon pea, Cajanus cajan (L.) Millsp. is one of the good host plants for lac cultivation after the correct identification of genotype.

\section{ACKNOWEDGEMENT}

The authors sincerely thank the Head, Department of Entomology; Dean, Rajasthan College of Agriculture and Director Research, MPUAT, Udaipur for providing the necessary facilities to conduct the research.

\section{REFERENCES}

Divakara, B.N. (2013). Exploration of lac cultivation on Non-traditional host F. macrophylla (Willd.) Kuntze Ex Merr. and it's possibility in understorey plantations of Dalbergia sissoo (Roxb). International Journal of Forest, Soil and Erosion. 3: 129-133.

Ghosh, J., Jyoti, A., Lohot, V.D., Sinha, N.K., Ghosal, S., Thamilarasi, K. and Thakur, V.V. (2018). Consequence of lac cultivation on Pigeon pea, Cajanus cajan (L.) seeds and seedling establishment. An International Refereed, Peer Reviewed and Indexed Quarterly Journal in Science, Agriculture and Engineering. 8: 289-291.

Ghosh, J., Lohot, V.D., Singhal, V., Ghosal S. and Sharma, K.K. (2014). Pigeon pea Lac insect interaction; Effect of Lac culture on grain yield and biochemical parameters in Pigeon pea. Indian Journal of Genetics and Plant Breeding. 74: $644-650$.
Kalahal, C., Swami, H. and Lekha. (2017). Productivity-linked parameters Cajanus cajan Linn. at Rajasthan. Journal of Entomology and Zoology Studies. 5(3): 1745-1751.

Kandasamy, T., Kumari, K., Ghosh. J., Tribhuvan, K.U., Lohot, V.D., Gargi, M. and Ghosal, S. (2020). EST-SSRs reveal genetic distinction between lac and grain yielding genotypes of Pigeon pea. Journal of plant Biochemistry and Biotechnology. 29: 61-472.

Kumari, K., Thamilarasi, K., Ghosh, J., Lohot, V.D. and Ghosal, S. (2019). Molecular diversity analysis of pigeon pea genotypes for scar marker development. International Journal of Chemical Studies. 6: 534-540.

Lohot, V.D., Ghosh, J., Ghosal, S., Thamilarasi, Gunjan and Sharma, K.K. (2018). Effect of lac culture on seed quality traits of Pigeon pea, Cajanus cajan (L.) Millsp. Journal of Entomology and Zoology Studies. 6(2): 2293-2298.

Mohanasundaram, A., Monobrullah, M., Sharma, K.K., Meena, S.C and Ramani, R. (2016). Lac insect and associated faunaA Practical Manual. ICAR-Indian Institute of Natural Resins and Gums, Ranchi (Jharkhand). 01-42 pp.

Mohanta, J., Dey D.G. and Mohanty, N. (2014). Studies on lac insect (Kerria lacca) for conservation of biodiversity in Similipal Biosphere Reserve. Journal of Entomology and Zoology. 2: $1-5$.

Singh, R. (2006). Applied Zoology Lac Culture. Department of Zoology Udi Pratap Autonomus Collage Varanasi, pp 2.

Swami, H., Kalahal, C., Lekha and Jain, D. (2017). Biology of Rangeenistrain of lac insect (Kerria lacca Kerr.) on Pigeon pea (C. cajan Linn.). Journal of Entomology and Zoology Studies. 5(5): 1648-1650. 